\title{
Apoiando o Ensino de Diagrama de Atividades através de um jogo educacional
}

\author{
Williamson Silva ${ }^{1}$, Igor Steinmacher ${ }^{2}$, Tayana Conte ${ }^{1}$ \\ ${ }^{1}$ Grupo de Pesquisa em Usabilidade e Engenharia de Software (USES) - Instituto de \\ Computação (IComp) - Universidade Federal do Amazonas (UFAM), Manaus, AM - \\ Brasil \\ ${ }^{2}$ Departamento de Computação - Universidade Federal de Tecnologia do Paraná \\ (UFTPR), Campo Mourão, PR - Brasil \\ \{williamson.silva, tayana\} @icomp.ufam.edu.br, igorfs@utfpr.edu.br
}

\begin{abstract}
Models are simplifications of the reality that help us to comprehend, analyze and design software. Therefore, it is necessary to support students while they are learning these models. One way to make this process more effective is by using alternative teaching methods, such as educational games. To facilitate the software models learning, we developed and evaluated an educational game called ActGame (Activity Diagram Game) which aims to support the students in the modeling of Activity Diagrams. This paper presents ActGame and a preliminary game evaluation. The results indicate that the game positively influenced motivation, user experience and student learning.
\end{abstract}

Resumo. Modelos são simplificações da realidade que ajudam a compreender, analisar e projetar o software. Logo, faz-se necessário auxiliar alunos enquanto estão aprendendo estes modelos. Uma maneira de tornar o ensino mais efetivo é utilizando métodos de ensino alternativos, como jogos educacionais. Para facilitar a aprendizagem de modelagem, foi desenvolvido e avaliado um jogo educacional chamado ActGame (Activity Diagram Game) que auxilia os alunos na modelagem de Diagrama de Atividades. Este artigo apresenta o ActGame e uma avaliação preliminar do jogo. Os resultados indicam que o jogo influenciou positivamente a motivação, a experiência do usuário e a aprendizagem dos alunos.

\section{Introdução}

A capacidade de abstração é considerada uma das habilidades mais importantes para estudantes, pois auxilia na elaboração de modelos utilizados durante o desenvolvimento de software (Sien, 2010). Esses modelos são simplificações da realidade que permitem aos profissionais compreender e analisar sistemas de software (Al-Tahat, 2014). No entanto, estudantes apresentam dificuldades para aprender estes modelos, tais como: dificuldade em entender a sintaxe e a semântica dos diagramas, dificuldade em organizar as informações nos modelos, dentre outras (Szmurło e Śmiałek, 2006; Sien, 2010; Lethbridge, 2014; Al-Tahat, 2014). Essas dificuldades podem afetar a qualidade do software final, pois os modelos que serão criados representarão o software de forma incompleta e incorreta (Sien, 2010; Lethbridge, 2014). 
Uma das razões para este tipo de problema pode ser a forma como a modelagem vem sendo ensinada (Szmurło e Śmiałek, 2006), uma vez que a forma tradicional ainda é a principal abordagem de ensino utilizada (Freeman et al., 2014). Logo, é necessário explorar novos recursos pedagógicos a fim de proporcionar aos alunos um aprendizado mais aprofundado, além de construir um ambiente de aprendizagem divertido e motivador (Petri e Chiavegatti, 2015). Um dos recursos pedagógicos disponíveis aos professores são os jogos educacionais, que têm por objetivo despertar os interesses dos alunos pelo conteúdo que está sendo ensinado (Souza e França, 2016). Contudo, Petri e Chiavegatti (2015) afirmam que os jogos existentes na literatura objetivam apenas relembrar os conceitos aprendidos na aula. Assim, os alunos não conseguem aplicar tais conteúdos de forma mais prática, como, por exemplo, na elaboração de um modelo.

Este artigo apresenta um jogo educacional chamado ActGame (Activity Diagram Game). O ActGame é um jogo baseado em cartas e tem por objetivo ensinar os alunos a construir um dos modelos ensinados nos cursos de computação, o Diagrama de Atividades (DA) da UML (Unified Modeling Language) (OMG, 2010). O DA é utilizado para representar, de forma mais detalhada, a lógica das atividades que podem ser realizadas no software (Booch et al., 2005). Este jogo utiliza alguns elementos de gamificação (Deterding et al., 2011), visando incentivar a competição entre os alunos durante a modelagem do DA. Para analisar a viabilidade do jogo em um ambiente acadêmico, foi realizada uma avalição experimental preliminar utilizando um modelo específico para avaliação de jogos educacionais, o MEEGA (Model for the Evaluation of Educational Games) (Savi et al., 2011). O ActGame foi utilizado por alunos de um curso de Ciência da Computação para avaliar o grau de aprendizado de DA após a utilização do jogo.

Este artigo está organizado da seguinte maneira: na Seção 2 são descritos os trabalhos relacionados ao ensino de modelos de software; na Seção 3 é apresentado o jogo desenvolvido para o ensino de diagrama de atividades; na Seção 4 é descrito o processo experimental do jogo e seus resultados. Por fim, na Seção 5 são mostradas as considerações finais e trabalhos futuros decorrentes desta pesquisa.

\section{Trabalhos Relacionados}

Os Diagramas de Atividades da UML têm sido amplamente utilizados na modelagem de fluxos de trabalho, processos de negócios e serviços, em que servem para diversos propósitos, desde documentação, definições de requisitos e especificações de casos de teste até simulação e geração de código (Booch et al., 2005). No entanto, não foram identificados na literatura jogos educacionais que explorem os conteúdos sobre DA (Wangenheim e Shull, 2009). Por outro lado, percebe-se que há várias abordagens de ensino sendo propostas visando auxiliar o ensino de outros modelos da UML.

Lethbridge (2014) propôs a ferramenta de modelagem Umple, projetada para ajudar estudantes e engenheiros de software a aprender e ensinar diagrama de classes. Tourtoglou e Virvou (2008) projetou um Sistema de Aprendizagem Colaborativo Apoiado por Computador que auxilia os estudantes na elaboração de diagramas da UML. Al-Tahat (2014) propôs um método instrucional para o ensino de UML com a ajuda de um ambiente 3D. Szmurło e Śmiałek (2006) desenvolveu um conjunto de boas práticas que objetiva ensinar os alunos a desenvolver os modelos da UML. 
Além destas abordagens, há várias outras abordagens que têm sido propostas para melhorar o ensino de modelos da UML. Assim, ajudando os alunos no desenvolvimento da habilidade de projetar modelos corretos e completos. Contudo, não foi identificado nenhuma abordagem ou jogo educacional que ensine os alunos a projetar o DA (Wangenheim e Shull, 2009). Dessa forma, este trabalho propõe um novo jogo educacional visando atender esta lacuna, conforme será mostrado a seguir.

\section{Jogo Educacional ActGame}

ActGame (Activity Diagram Game) é um jogo educacional baseado em cartas, que visa ajudar os alunos durante a modelagem de DA. A fim de ajudar os alunos, o jogo auxilia na identificação dos elementos do DA e também na construção do diagrama a partir de uma descrição textual. Com o intuito de facilitar o entendimento dos alunos em relação à notação do DA, as cartas do jogo foram criadas tomando como base os principais elementos do DA (Booch et al., 2005).

O ActGame foi projetado para ser utilizado individualmente e em grupo. Individualmente, apenas um jogador irá interagir com o jogo seguindo suas etapas. Em grupo (equipes de três a cinco jogadores), os jogadores devem discutir livremente o problema e em seguida realizar a modelagem seguindo as etapas do jogo. O jogo possui cinco etapas: Identificação das Swimlanes (Etapa 1), Identificação do Nó de Início (Etapa 2), Identificação das atividades (Etapa 3), Agrupamento das atividades (Etapa 4), Transição das Atividades (Etapa 5), Identificação do Nó Final (Etapa 6). Cada etapa possui 4 cartas: Passo da Modelagem, Perguntas-Guia, Dicas e Exemplo. A descrição das cartas do jogo está na Tabela 1.

Tabela 1. Descrição das Cartas utilizadas no jogo.

\begin{tabular}{|c|l|}
\hline Tipo de Carta & \multicolumn{1}{c|}{ Descrição } \\
\hline $\begin{array}{c}\text { Carta Passo da } \\
\text { Modelagem }\end{array}$ & $\begin{array}{l}\text { Esta é a primeira carta a ser utilizada em cada uma das etapas do jogo. Nessa carta há: uma heurística de } \\
\text { construção que ajuda a identificar os elementos do diagrama a partir da descrição textual (Figura 1 Item } \\
\text { A);Instruções de Construção que ajudam a inserir esses elementos no diagrama (Figura 1 Item B);um } \\
\text { exemplo do elemento (Figura 1 Item C); e um exemplo de aplicação que mostra de forma ilustrativa } \\
\text { como extrair o elemento do diagrama de atividades a partir de uma descrição textual (Figura 1 Item D). }\end{array}$ \\
\hline $\begin{array}{c}\text { A carta Perguntas-Guia e Dicas apresentam, respectivamente, perguntas (Figura 1 Item E) e dicas (Figura } \\
\text { Carta Perguntas- } \\
\text { Guia e Carta Dicas A) que direcionam os jogadores na identificação dos elementos e na construção do DA. Além } \\
\text { disso, cada carta possui um exemplo de como identificar o elemento a partir de uma descrição textual } \\
\text { (Figura 1 Item F e Figura 2 Item B). }\end{array}$ \\
\hline Carta Exemplo & Esta carta apresenta mais um exemplo de como o elemento deve ser modelado no DA (Figura 2 Item C). \\
\hline
\end{tabular}

Para motivar os estudantes durante a construção do DA, o jogo emprega elementos de gamificação (Deterding et al., 2011). Cada tipo de carta possui uma pontuação diferente e ao utilizá-las os jogadores ganham um emblema com uma pontuação (Figura 3). Por exemplo, quando os jogadores utilizam apenas um tipo de carta em uma etapa do jogo, eles ganham um emblema com a pontuação da carta utilizada. Porém se utilizarem as cartas combinadas, por exemplo, a carta Passo da Modelagem e a carta Exemplo, estes ganham os pontos referentes às duas cartas. $\mathrm{O}$ objetivo é fazer com que os jogadores utilizem mais cartas possíveis para que aprendam a modelar. Além disso, há mais dois emblemas com uma pontuação extra para a equipe (a) que terminar primeiro a modelagem e (b) cujo diagrama estiver mais correto e completo. Ganha o jogo a equipe que tiver mais pontos no final. Vale frisar que o professor atua como moderador do jogo. O moderador deve explicar as regras do jogo às equipes, entregar a primeira carta (Passo da Modelagem) e informar quais cartas ainda 
estão disponíveis, caso a equipe solicite também outra(s) carta(s). Além disso, o moderador deve anotar as cartas solicitadas por cada equipe em cada etapa do jogo.

No início do jogo, todos da equipe recebem uma descrição textual com o problema deverá ser modelado (cenário, especificação de casos de uso, dentre outros). Recomenda-se que a equipe leia e discuta a descrição textual em conjunto para que todos obtenham o mesmo nível de entendimento sobre o problema. Após isso, os jogadores recebem as cartas e são informados que devem seguir as instruções de construção/ identificação que há em cada carta. Por exemplo, na carta Passo da Modelagem 1 (Identificação da Swimlane) há uma heurística que ajuda os jogadores a identificar quem são os atores envolvidos no cenário, então os jogadores começam a identificar na descrição textual os atores que podem ser as swimlanes do DA. Portanto, espera-se que seguindo as instruções das cartas em cada etapa do jogo, os jogadores identifiquem os elementos e modelem o diagrama. A versão completa do ActGame está disponível em um relatório técnico (Silva et al., 2017).

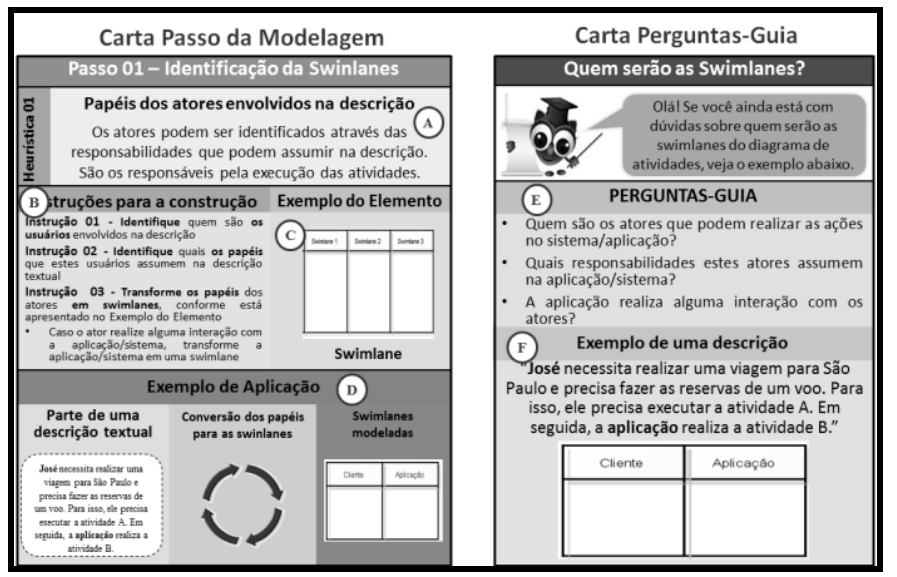

Figura 1. Exemplo das cartas Passo da Modelagem e Perguntas-Guia.

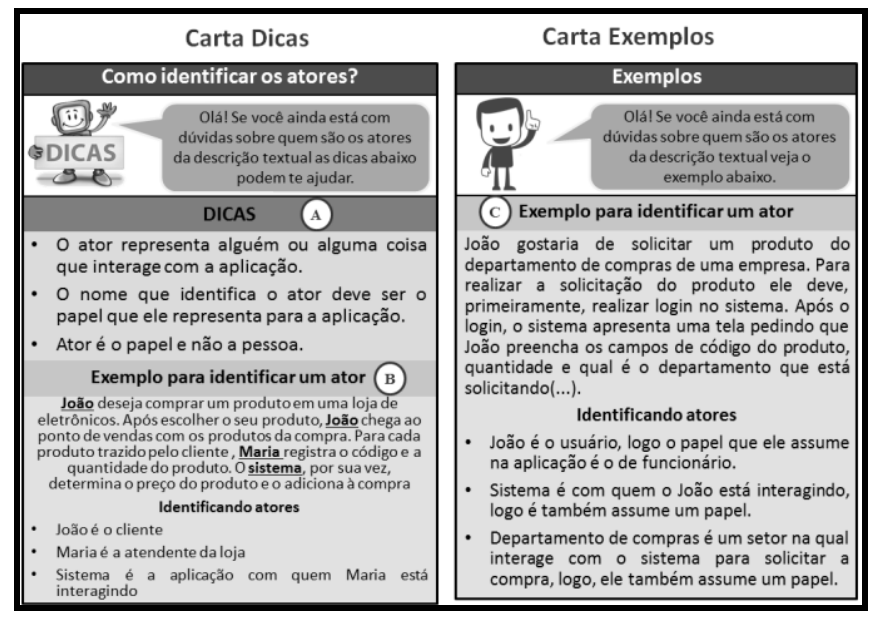

Figura 2. Exemplo das cartas Dicas e Exemplo.

Com o objetivo de verificar a efetividade da aprendizagem, motivação e experiência do usuário ao utilizar o jogo ActGame, realizou-se uma avaliação do jogo utilizando o modelo MEEGA proposto por Savi et al. (2011). 


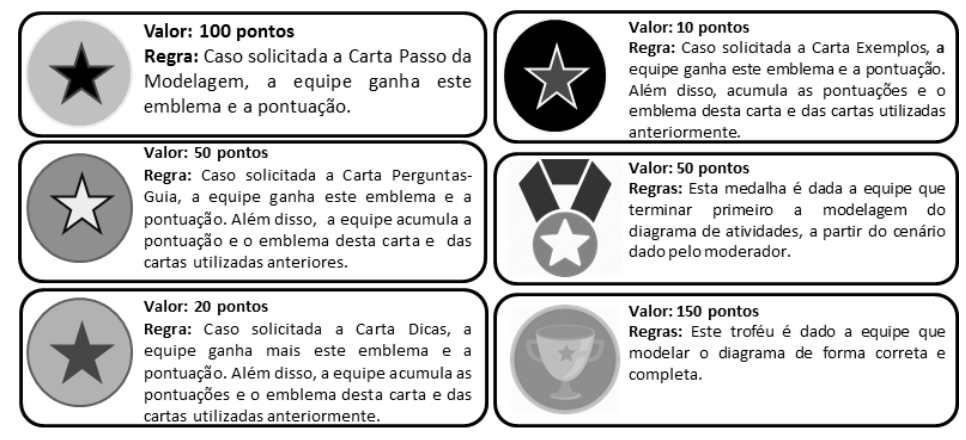

Figura 3. Pontuação e Regras utilizadas no jogo.

\section{Avaliação do Jogo ActGame}

Savi et al. (2011) afirmam que os jogos propostos com o objetivo de apoiar ao processo de ensino e aprendizado devem ser avaliados para garantir que os mesmos tenham um efeito positivo no aprendizado do jogador. Desta forma, para a avaliação do aprendizado com o jogo ActGame, foi utilizado o modelo MEEGA (Savi et al., 2011). A avaliação do jogo foi realizada com 29 alunos voluntários do $5^{\circ}$ período do Curso de Ciência da Computação da Universidade Federal do Amazonas. Antes da avaliação do jogo, todos os alunos assistiram a um treinamento em que foi realizada uma breve contextualização sobre DA, além de uma contextualização sobre como seria realizada a avaliação. Após isso, os alunos foram convidados a assinar um termo de consentimento, no qual concordavam participar do estudo. Apesar dos vinte e nove alunos terem assinado o termo, apenas dezenove concordaram em responder o questionário de avaliação.

A avaliação ocorreu em duas etapas: (a) construção do diagrama utilizando o jogo; e (b) preenchimento do questionário de avaliação. Na primeira etapa, os alunos foram divididos em equipes definidas por conveniência, em que eles decidiram quais alunos fariam parte do seu grupo. Ao todo, foram formados seis grupos, com 4 ou 5 participantes por grupo. O tempo médio de utilização do jogo pelos participantes foi de 55 minutos (tempo mínimo 35 minutos; máximo 60 minutos). Isto indica que é viável a utilização do jogo durante uma aula. Na segunda etapa, 19 alunos responderam ao questionário do modelo MEEGA.

O MEEGA é um questionário padronizado proposto por Savi et al. (2011) que possibilita avaliar jogos educacionais. O questionário possui vinte e sete itens fixos divididos em três categorias (Motivação, Experiência do Usuário e Aprendizagem) e onze dimensões. Cada item do questionário é respondido em uma escala de Likert de cinco pontos com alternativas de resposta variando de discordo fortemente (-2) a concordo fortemente (2). Para avaliar o impacto na aprendizagem, o MEEGA ainda possui perguntas customizadas aos objetivos no jogo em que os alunos realizam uma autoavaliação sobre o conteúdo antes e depois de utilizarem o jogo. Além disso, Foi acrescentada três questões abertas para permitir um melhor entendimento das respostas dos participantes em relação às categorias: (a) "Do que você gostou no jogo"; (b) "Do que você não gostou no jogo?"; e (c) "O que você mudaria para melhorar o jogo". 


\subsection{Análise dos Resultados da Categoria Motivação do MEEGA}

Com relação à categoria Motivação, avaliou-se as seguintes dimensões: Satisfação, Confiança, Relevância e Atenção. A Figura 4 mostra as afirmativas relacionadas a cada uma das dimensões e o grau de concordância com relação a cada afirmação. No que diz respeito a dimensão Satisfação, $74 \%$ dos participantes concordaram que conseguiam avançar no jogo devido ao esforço pessoal. No item que avalia se o participante teria oportunidade de utilizar na prática o que foi aprendido no jogo (item 02), houve concordância de 58\% dos participantes. O participante P08 comentou que gostou de "como o jogo faz você identificar primeiros as swimlanes e as atividades antes de aplicar na prática" e o participante $\mathrm{P} 01$ frisou que "percebi que todos os integrantes da equipe estavam motivados para solucionar o desafio".

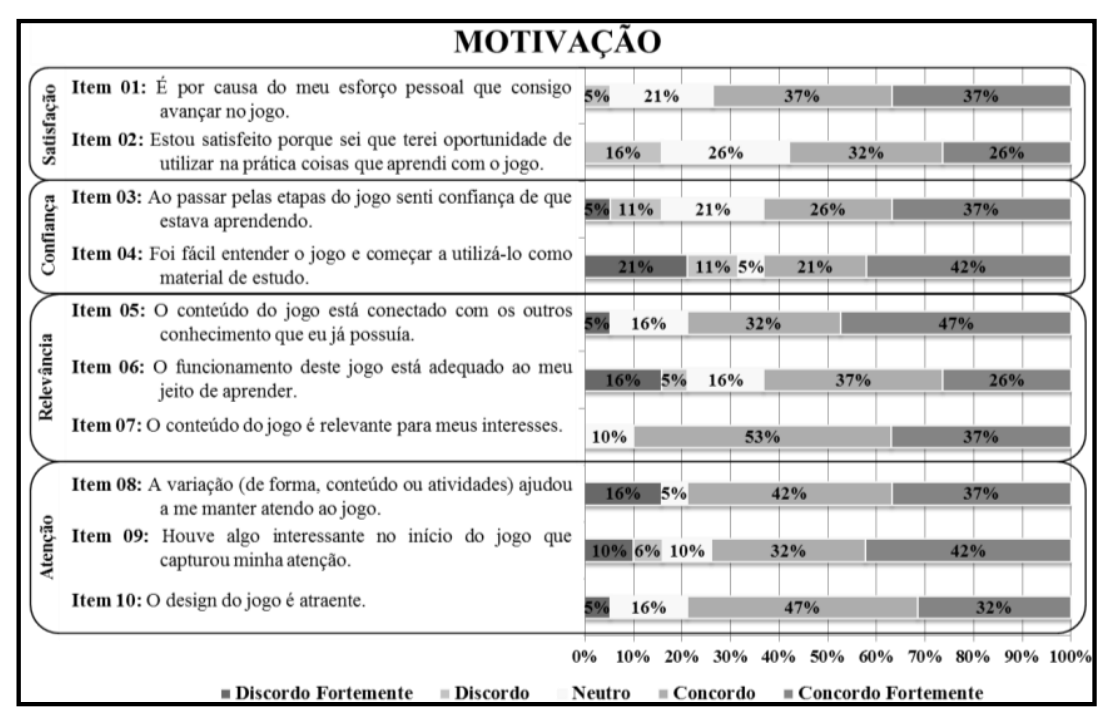

Figura 4. Gráfico de Avaliação da categoria Motivação.

No que se refere a dimensão Confiança, obteve-se $63 \%$ de concordância em seus dois itens: o aprendizado obtido ao passar pelas etapas do jogo (item 03) e se o jogo foi fácil de entender e começar a jogar (item 04). Apesar de não haver muitos participantes discordando ou permanecendo neutro, percebe-se que esta dimensão possuiu a maior quantidade de discordâncias. Logo, este aspecto do jogo merece ser melhor investigado junto aos alunos para buscar formas de melhorá-lo.

Sobre a dimensão Relevância, dois itens foram bem avaliados. O item que avalia se o conteúdo estava relacionado com outros conhecimentos que já possuíam (item 05), obteve concordância de $79 \%$ dos participantes. Enquanto que $63 \%$ dos participantes concordaram que o funcionamento do jogo é adequado. Além disso, $90 \%$ dos participantes concordaram que o conteúdo do jogo é importante para os interesses deles.

Por fim, quanto a dimensão Atenção, 79\% dos participantes concordaram que a variação do jogo ajudou a mantê-los atentos e $74 \%$ dos participantes consideraram que houve algo que capturou a sua atenção ao jogo. Sobre o design do jogo, 79\% consideram que o design do jogo é atraente. O comentário do participante P12 reforça os resultados desta dimensão, pois, segundo ele, o jogo "é uma atividade didática lúdica". 


\subsection{Análise dos Resultados da Categoria Experiência do Usuário do MEEGA}

Nesta categoria foram avaliadas cinco dimensões: Competência, Diversão, Desafio, Interação Social e Imersão. A Figura 5 mostra as afirmações relacionadas a cada uma das dimensões e o grau de concordância com relação a cada afirmação. Com relação à dimensão Competência, 64\% dos participantes tiveram sentimentos positivos de eficiência do jogo, enquanto que $84 \%$ afirmam que conseguiram atingir os objetivos do jogo por meio de suas habilidades.

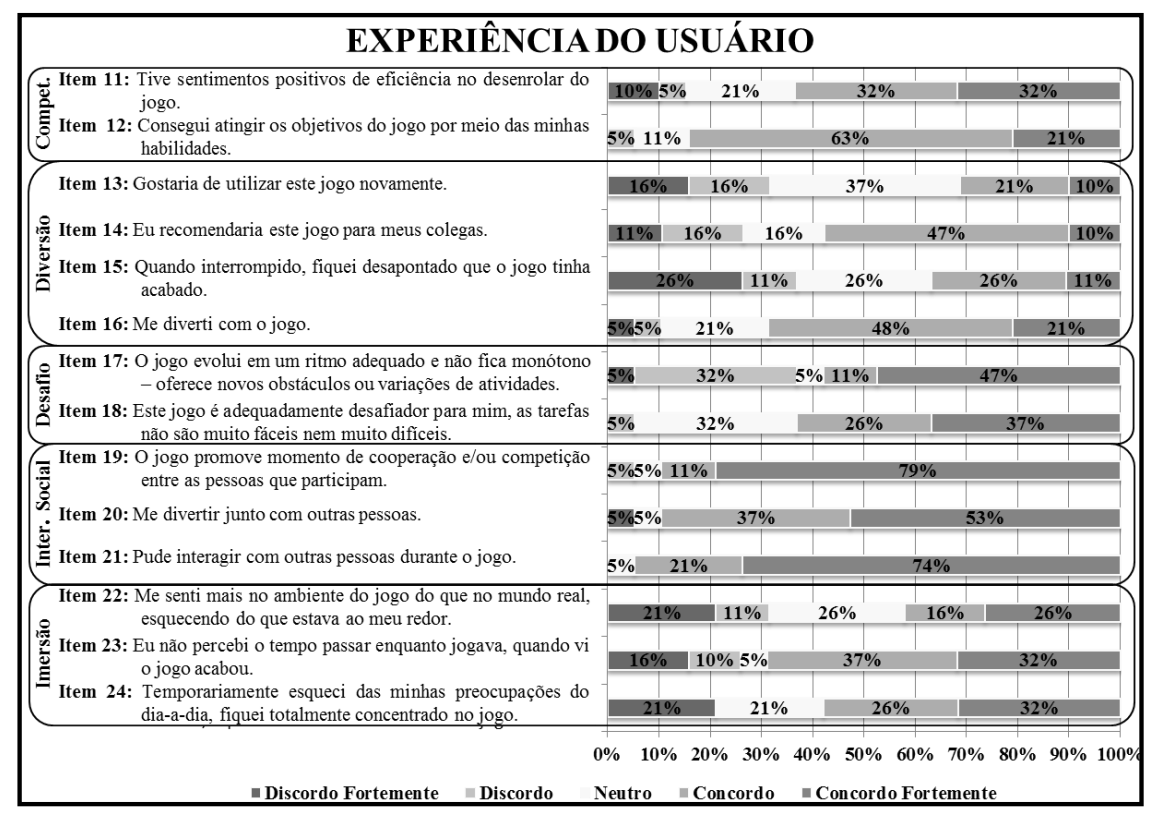

Figura 5: Gráfico de Avaliação da categoria Experiência do Usuário.

Na dimensão Diversão, dois itens foram bem avaliados. Entretanto, em outros dois, nota-se uma grande quantidade de participantes discordando ou permanecendo neutros. Para o item que avalia se os participantes gostariam de utilizar o jogo novamente (item 13), houve concordância por parte de apenas 31\% dos participantes. Apesar desta baixa concordância, $57 \%$ dos participantes afirmaram que recomendariam o jogo para seus colegas. Já o item que avalia se os participantes ficaram desapontados com a interrupção do jogo (item 15), 37\% dos participantes concordaram. No entanto, $69 \%$ dos participantes afirmaram que se divertiram com o jogo, tal fato foi ressaltado pelo participante $\mathrm{P} 05$, que gostou "da maneira criativa que foi elaborada para aprendermos a modelagem" do diagrama de atividades.

No que diz respeito à dimensão Desafio, 58\% concordam que o jogo evolui em um ritmo adequado e não fica monótono, seja oferendo obstáculos ou situações, conforme relatado no comentário do participante. Além disso, 63\% afirmam que o jogo possui tarefas desafiadoras. Apesar deste item ter a maior porcentagem de discordâncias (32\%) na dimensão Experiência do Usuário, o participante P09 avaliou positivamente o jogo: "gostei da forma que o jogo fazia os integrantes interagirem para solucionar o problema junto com os obstáculos que apareciam no decorrer do jogo". Além disso, o participante P11 frisou que gostou do "dinamismo e a agilidade do processo" do jogo, avaliando positivamente a variação das atividades. 
A dimensão Interação Social foi a melhor avaliada nesta categoria. Percebeu-se que $90 \%$ dos participantes concordaram em dois itens: no item que avalia se o jogo promove a cooperação e a competição entre as pessoas que participam (item 19) e no item que avalia se os alunos se divertiam com os outros participantes enquanto utilizavam o jogo (item 20). Com relação à interação com outras pessoas do grupo (item 21), houve uma concordância de $95 \%$ dos participantes. O participante P16 comentou que gostou da "interação com o grupo e a discussão de ideias" e o participante P03 frisou que gostou "do forte espírito em equipe" que o jogo proporciona. Além disso, o participante P17 afirmou que o jogo "é dinâmico e envolve a percepção $e$ a competitividade" entre as equipes.

Para a dimensão Imersão, o item que avalia se o participante se sentiu mais no ambiente do jogo do que no mundo real, obteve uma concordância de apenas $42 \%$ (item 22). No entanto, $69 \%$ dos participantes não perceberam o tempo passar enquanto jogavam e 58\% afirmam que esqueceram as preocupações enquanto estavam jogando.

\subsection{Análise dos Resultados da Categoria Aprendizado do MEEGA}

A Figura 6 apresenta o gráfico dos resultados da categoria Aprendizagem. Para essa categoria, houve uma concordância de $79 \%$ sobre o item que avalia se o jogo contribui para o desempenho profissional do participante (item 25). No item que avalia se o jogo foi eficiente para a aprendizagem dos participantes em comparação com outras atividades (item 26), houve uma concordância de 72\%. Além disso, $79 \%$ dos participantes concordam que o jogo contribuiu para a aprendizagem na disciplina.

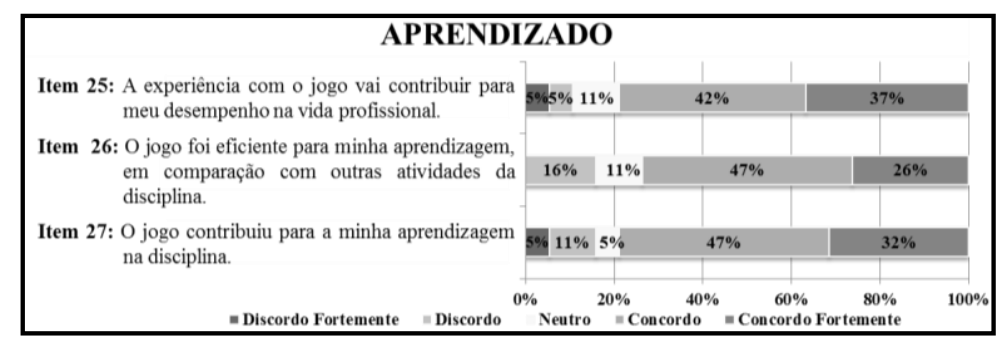

Figura 6. Gráfico de Avaliação da categoria Aprendizagem

Esses resultados são reforçados pelos comentários dos participantes. O participante P02 afirmou que "(o jogo) proporcionou ótimo aprendizado". Já o participante P18 disse que "as etapas do jogo facilitam no aprendizado" e o participante P10 frisou que o jogo é "uma alternativa ao padrão aula com slides. (o jogo é) bem criativo, conta com vários conceitos úteis para o desenvolvimento do conhecimento".

Savi et al. (2011) sugerem avaliar também a aprendizagem dos alunos através da autoavaliação em relação ao seu aprendizado sobre o conteúdo que foi ensinado. Os conceitos avaliados estavam relacionados aos elementos do DA e foram avaliados do ponto de vista de três objetivos, antes e depois de utilizar o jogo: (a) lembrar o que é, (b) compreender como funciona e (c) aplicar na prática. Os alunos deveriam atribuir uma nota de 1 a 5, onde 1 estava relacionado a "pouco conhecimento" e 5 a "muito conhecimento". A Figura 7 apresenta o gráfico com as médias de autoavaliação da aprendizagem dos alunos em relação aos elementos do DA, antes e depois do jogo. É possível perceber que houve um aumento no nível de conhecimento dos alunos para 
todos os elementos do DA. Este resultado é positivo, pois indica que o jogo alcançou seus objetivos em relação ao auxílio na aprendizagem de DA.

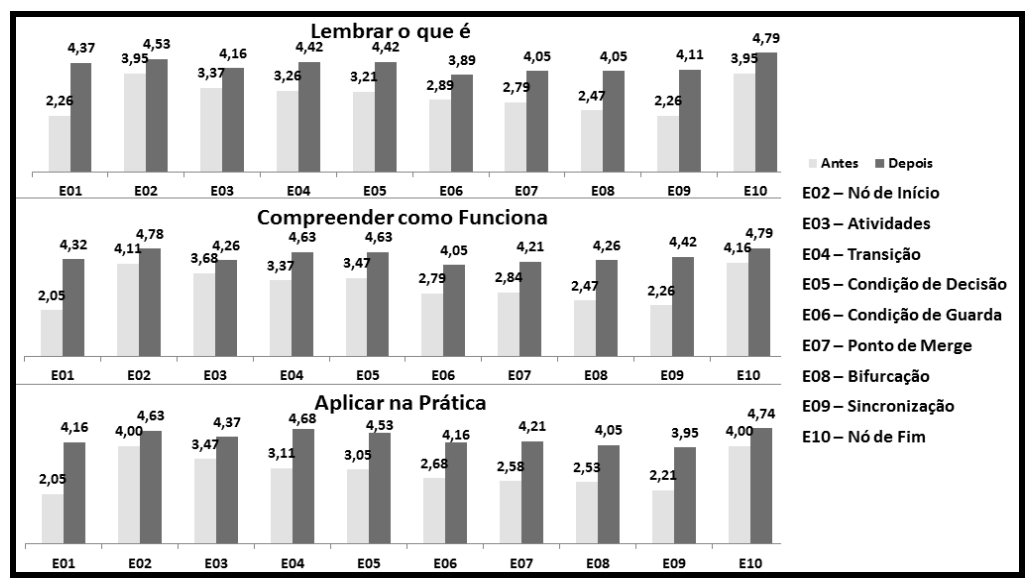

Figura 7. Gráfico das medidas de autoavaliação.

\section{Considerações Finais e Trabalhos Futuros}

Este artigo apresentou o jogo ActGame (Activity Diagram Game), um jogo baseado em cartas, que tem como objetivo auxiliar no processo de ensino e aprendizagem de Diagrama de Atividades. Foi realizada também uma avaliação experimental inicial utilizando o modelo MEEGA, proposto por Savi et al. (2011).

Através dos resultados da avaliação do jogo, no que diz respeito à categoria Motivação, percebeu-se que o jogo teve efeito positivo. O design do jogo foi considerado atraente, o conteúdo relevante e conectado a outros conhecimentos, além de ter ajudado a manter os alunos atentos ao jogo. Em relação à categoria Experiência do Usuário, os resultados também mostraram que o jogo proporcionou uma experiência de uso relativamente positiva aos alunos, com destaque para a dimensão interação social. Além disso, os resultados mostraram que há indícios sobre a utilidade do jogo para a aprendizagem de DA. Este resultado também foi percebido na média das concordâncias dos participantes com relação à categoria Aprendizagem e na autoavaliação realizada pelos alunos. Apesar disso, observou-se também pontos de melhorias no jogo, tais como, melhorar o jogo para que os alunos se divirtam e se sintam imersos enquanto estiverem jogando e fazer com que os alunos se sintam seguros que estão modelando um DA de forma correto.

Baseado nisso, como trabalhos futuros pretende-se realizar uma nova versão do jogo, a fim de proporcionar um aumento nas competências dos estudantes. Além disso, pretende-se realizar um estudo comparando o uso do ActGame com outras abordagens de ensino. Espera-se desta forma, contribuir para a melhoria do ensino de diagrama de atividades em cursos de Computação no Brasil.

\section{Agradecimentos}

Os autores agradecem o apoio financeiro da CAPES e da FAPEAM, através do processo 062.00578/2014; e a CAPES através do processo 175956/2013. Agradecemos também aos participantes do estudo e aos pesquisadores do USES-UFAM pelas contribuições na execução desta pesquisa. 


\section{Referências}

Al-Tahat, K. (2014). "An innovative instructional method for teaching object-oriented modelling”. In Int. Arab Journal Information Technology, v.11, n.6, p.540-549.

Booch, G., Rumbaugh, J., e Jacobson, I. (2005). "Modeling Language User Guide”. In The Addison-Wesley Objetc Technology Series (2nd Edition).

Deterding, S., Sicart, M., Nacke, L., O’Hara, K., e Dixon D. (2011). “Gamification: Using Game Design Elements in Non-Gaming Contexts". In Annual Conference Extended Abstracts on Human Factors in Computing Systems, p. 2425-2428.

Freeman, S., Eddy, S. L., McDonough, M., Smith, M. K., Okoroafor, N., Jordt, H., e Wenderoth, M. P. (2014). "Active learning increases student performance in science, engineering, and mathematics". In National Academy of Sciences of the United States of America, v. 111, no 23, p.8410-8415.

Lethbridge, T. C. (2014). "Teaching modeling using Umple: Principles for the development of an effective tool". In: 27th Conference on Software Engineering Education and Training (CSEE\&T), p. 23-28

OMG Unified Modelling Language Superstructure $\quad$ - version 2.3. http://www.omg.org/spec/UML/2.3/, 2010

Petri, G., e Chiavegatti, N. C (2015). "Um Role Playing Game para o Ensino de Elicitação e Análise de Requisitos". In Revista Novas Tecnologias na Educação, v.13, no1, p. 01-10.

Savi, R., Wangenheim, C., e Borgatto, A. (2011). "Um Modelo de Avaliação de Jogos Educacionais na Engenharia de Software". In XXV Simpósio Brasileiro de Engenharia de Software (SBES 2011), p. 194-203.

Sien, V. (2010). "Teaching Object-Oriented Modelling using Concept Maps". In Journal Electronic Communications of the European Association of Software Science and Technology, v. 34, p. 1-13.

Silva, W., Steinmacher, I., e Conte, T. (2017). “ Um jogo educacional que apoia o ensino de Diagrama de Atividades". In Relatório Técnico TR-USES-2017-0009. Disponível em: http://uses.icomp.ufam.edu.br/relatorios-tecnicos/.

Souza, M. V. R., e França, C. (2016). "O que Explica o Sucesso de Jogos no Ensino de Engenharia de Software? Uma Teoria de Motivação". In 24 Workshop sobre Educação em Computação, p. 2255-2264.

Szmurło, R., e Śmiałek, M. (2006). "Teaching software modeling in a simulated project environment”. In International Conference on Model Driven Engineering Languages and Systems, p. 301-310.

Tourtoglou, K., e Virvou, M. (2008). "User stereotypes concerning cognitive, personality and performance issues in a collaborative learning environment for UML” In: New Directions in Intelligent Interactive Multimedia, p. 385-394

Wangenheim, C. G. V., e Shull, F. (2009). “To game or not to game?". In IEEE Software, vol. 26, nº. 2, p. 92-94. 